\title{
Inspiring Creative Thinking Ability in Multicultural Background and Promoting Educational Development in Cross - disciplinary education
}

\author{
Lirong Yang \\ Facultad de Bellas artes, Universidad de Barcelona, Barcelona 08011, Spain
}

yanglirong1704@126.com

Keywords: Multi-Culture, Art Creativity, Interdisciplinary Education.

\begin{abstract}
Contemporarily, rapid process of globalization and population flow is no longer a new phenomenon. Under such background, multiculturalism promotes social integration, and development of innovative industries. The inherent characteristics of multiculturalism also improve the re-contribution of creative inspiration, thus promoting the development of new culture. This article proposes to analyze from the perspective of multicultural background, and evaluate the social identity of art education and the innovative interdisciplinary education model of art education.
\end{abstract}

\section{Multicultural Mobility Inspires Creative Inspiration and Builds New Art Space}

\subsection{Cultural Mobility Inspired Art Learning and Creation}

In contemporary rapid process of globalization, population flow is no longer a new phenomenon. In the late 80s of last century, the European Union formally raised the term mobilite that was gradually accepted and implemented by pedagogy. In fact, due to the acceleration of globalization, regardless of individuals or groups, willing or unwilling population flow, population mobility will be globalized in macro-level and personal experiences will be individualized in micro-level through the change and integration of political, economic and ecological environments; the phenomenon also reflects the constant change of people's identity and the increase in uncertainty. This also leads to the creation of more multicultural, interdisciplinary and artistic educational methods in the field of art.

What is urging us to distinguish population mobility from the concept of the flow of population and land are that the development of artificial intelligence and globalization. Because the contemporary term is no more only refers to the displacement of individuals and capital, also includes the changes of migrated people in the new environment, such as social relations, intercultural communications, differentiation in customs and the differences in image symbols. In other words, after the migration process (changing the resident and living environment), the cultural background of migrants not only bring the cultural exchange and collision to the new environment, but also create a "third culture", which means, multicultural reintegration, through personal thinking and experience shaped by cultural impact.

In art education, intercultural art learning and teaching, other than only through the film and television images and historical literatures, also can create collision between cultures through the form of cultural exchange. In major art institutions, mainly through international students or exchange of students between colleges, and through the cooperative art exhibition between organizations or galleries cooperation can also achieve short-term communication of art works. There may be a variety of mobile relationships between individuals and groups at different times; this can also lead to a series of complex cohesion and division by the group of people who are moving through experiences with tension relationship and differences such as observation, novelty, exclusion, acceptance, ambiguity, then triggering the re-creation of the inherent creative system. Whether it is for the original immobile groups or migrant groups (or individuals) are activated manufacturers of "new culture space". Through the integration of multiculturalism can not only produce new things, but also training the participants outside the adaptability, acceptance, social integration and other sociological, humane and other issues. These abilities have been improved, stimulating the creation of art and the perception of things, as well as thinking about the diversity of dimensions. 


\subsection{Multicultural Flow of Metaphorical Regeneration of New Art Cultural Space}

Multiculturalism itself has this kind of mobility, through the cultural background, the purpose of different people, the transmission of their own experiences, language, cultural differences, at the same time, promotes the pace of globalization. This non-linear, fragmented reproduction, often metaphorically presented, it prompted us through a multi-dimensional perspective to look at the problem and examine the past experience; beyond the inherent range of thinking, and it can be pushed to the source of creative ideas. The creative cultivation of the art education model needs to blur the boundaries of the original society and the inter-ethnic intercourse through the multicultural characteristics (metaphor and mobility), makes the culture more transparent and open, then the artistic creation, the ability to create new cultures, new images can become more sensitive and easy.

Excellent artists often have the prospective and behavioral critique of ideas, and they are used to breaking the routine and trying to reflect on it. The multiculturalism provides a well-thought-out platform that, by understanding the culture, customs, thinking patterns, thinking ideas of different ethnic groups or social groups, learn ways of empathy, just like metabolism, and to regenerate new social spaces. Social space of the mobile body, it exists in different time and space, experiencing a variety of changes. This series of process evolution, regeneration of new cultural convergence and social relations, metaphor is full of conflict, harmony and other contradictory vocabulary, but through multi-dimensional perspective to achieve speculative results. In terms of sociological and anthropological approaches, this metaphor of mobility interacts with artistic creation, inspires people to find identity in the background of identity, through different levels of testing and embodied in art teaching, what are also the re-creation of new culture, new language, and the concept of new space. Seeking common ground while reserving differences are not only make society more inclusive, but also produce a new culture on a more respectful basis, and through a variety of forms of evolution, this diversification raises the creativity and artistic aesthetics that adapt to the development of the times.

\section{Multiculturalism Promotes the Social Identity and Derivatives of Artistic Creation}

\subsection{Multiculturalism Brings About Social Identity}

The contemporary phenomenon and effects are sometimes surprising under a such rapid development of globalization. Although the voice of anti-globalization has never ceased, most people through the multicultural learning and integration, opened up the eyesight of theirselves, the awareness of the whole world are constantly updated and adjusted, it is undeniable that multicultural Interaction is constantly promote the development of globalization, at the same time, there have been on the identity and ethnic integration and other issues, these contradictions are obvious. Perru Anderson points out that "multiculturalism does not mean that cultures are simply coexisting in a broad world, and that culture is not as contradictory as" nation "and" social class. "Because culture does not have any derogatory connotations, it becomes ideal "Hans George Gadamer argues that" the other person who learns to be the other is a 'dialogue body' challenge, and it is this view that the mutualism is likely to change our contradictions in identity." Every one Culture is thinking, managing and changing its heritage, will be in accordance with the existing way to think, manage, change the existing things.

Multicultural adaptation can be found in the sense of social belonging, cultural adaptation is a double debugging, both on their own debugging and social debugging. The sense of belonging to the social environment is not passive, but in order to survive and strive for a better life, and the response to change. When try to find a sense of social belonging in the process of cultural adaptation, the individuals will take different strategies to deal with the situation of multiculturalism. Anthropologist CK Kluckhohn argues that "so-called culture refers to all forms of life created in history, including explicit and invisible, including reasonable and unreasonable, that they exist as a potential guide for people's behaviour at some point." Culture in learning and inheritance has been revised and innovated, but only in the inheritance can be innovated. Among those values are the core of culture and the most difficult to understand. Researchers believe that the dominant culture, is the culture that we can feel, such as art, clothing, food, architecture, etc., they belong to a small part of the culture, just like the 
part of an iceberg above the water; and below the water there is the much more extensive part, including the concept of time and space, communication model, a sense of accomplishment, the patterns of the control of emotions, values, world views, etc., these are the foundation of culture. If people from different cultural backgrounds do not understand the diversity and complexity, there is a conflict in the process of interaction.

Under these abstract factors, the seeking process of subtle transformation within complicated factors in multicultural education makes it important that multicultural creation occupies and coordinates the process of interaction. From the point of view of school education, the "multicultural luggage" is a propeller, and a large part comes from students, through direct communication and learning, can produce intuitive cultural reflection and rethink their own cultural characteristics and other cultural characteristics. Under the premise of recognizing cultural differences, they have cultural equality and multicultural respect.

\subsection{Artistic Creation Promotes Multicultural Interaction and Inclusion}

Semiotics and imagination make people get a sense of identity and symbolism. Images are seen as the most widely communicated, closely related, easy to remember patterns, and are the easiest to change the views of different cultures. Image symbolization is used to explain the ambiguous concepts between vision, words, sounds, emotions.

For example, in 2013, at the department of arts graduate course in the University of Barcelona, mentor Domenec Colbella through the same kind of painting tools, music background as a medium, a collective art creation. At the beginning, students flocked together by ethnic and regional characteristics and create works, after the first round of creative exchanges, ethnic, geographical and other characteristics were disrupted, and closed cultural traditions were broken. It is found that the same cultural background of the painting creation there is some kind of difficult to break the inherent attitude, this time to carry out painting practice, the original concerns, barriers are reduced, students are more willing to go out and accept the enthusiasm of new culture and the innovation of thinking. The whole group of the atmosphere becomes more inclusive, after a period of running and change, in the last few rounds of painting creation, the whole group presents new diversified artistic characteristics. Most of the people in this collective creation of the media to find a sense of collective identity and a sense of belonging, each person's work in the initial have a new interpretation. This kind of different culture, different imagination of re-creation, is the best embodiment of multi-cultural rational integration.

\subsection{Multicultural Derivatives - Cross Images}

"The image itself is not simply a description of the reality and move, he is also a reality, has its own characteristics and transmission of the way", as Gervereau interpreted [1]. The expression of visual images through the multicultural features, with a variety of hidden words and manifestations, is also brought together a variety of themes and a clear creative environment, through the transfer of original means, stitched and recreated by the artist's own elements and foreign cultural. For example, Andy Warhol based on the existing form of goods, cheap food, political figures, popular stars and other images of the screen printing of the creative form of his inherent social plot of the sense of belonging and foreign culture of the collision. Although he has said that "I do not think my art has any lasting value." But the artistic value of different artistic prices, it is often beyond the auction house selling, the real value is to stimulate and derive more artistic life. Andy Warhol creates and spawns new values and new ideologies about symbolic symbolism and diversity in symbolic forms such as painting, printing, photography, and imagery.

The analysis to the image needs a global vision, think of the fusion that globalization to bring human's communications and promotional methods and business, the creation and development brought by globalization for works of art, all of them gave birth to industry consortium and vertical integration. These are the background elements of art and visual advertising, as well as the ability to cultivate multicultural reading comprehension. Image signs in the visual advertising is about the expression of the meaning of the economic and functional strategies, this diversity of image expression, we can also be called "cross-image." And the expression of a hybrid product, widely circulated, used, recognized and recognized, is bound to have aesthetic considerations, the idea of 
both in the analysis of images or other materials, should go beyond the traditional icon recognition (such as the major successful product logo). Visual communication as an economic performance art, but also the reproduction of culture and business, in order to read an ad and art cultivation inseparable.

\section{Intercultural Acculturation and Interdisciplinary Education}

\subsection{Cross-Cultural Integration}

The cultural adaptation generated by multicultural acculturation is originally proposed by anthropologists. American anthropologist Redfield R. Riedfield, R. Linton, and M. Herskovits proposed the concept of anthropological acculturation that is, "between several groups of different cultures, with continuous, direct contact, resulting in one or both of the original cultural patterns change." The famous cross-cultural psychologist Bailey J.W.Berry more systematically put forward the concept of acculturation and individual psychological framework, especially the psychological acculturation. He made it clear that the concept of acculturation includes a double process of cultural and psychological changes that occur by two or more members of a cultural group due to contact. In his view, the complete acculturation must include two levels, one is the culture level or group level cultural / group level on the acculturation, that is, cultural contact groups in the social structure, economic base and political organization and other aspects of the changes. This is not an individual psychology, but he determines the nature of acculturation, and is the starting point and stage of individual psychological acculturation; the second is in the psychological level or individual level psychological / individual level acculturation, that is involved in cultural contact in the individual, , Diet and other acts, values, attitudes and even identity changes occur. They analyze and investigate the four phenomena through integration, assimilation, separation, marginalization, and list the problems and solutions that arise in multiculturalism. [2]

With the development of socio-economic status, a variety of educational modes is introduced to meet the requirements of cross-cultural communication, people give such kind of education abundant cultural content, the function of cross-cultural creation can demonstrate its unique performance better when under the contexts of language, art, film and television education. Innovation is an inexhaustible motive force for the progress of human culture, and the relationship between educational innovation and cultural innovation is interchangeable. Education is the basis of all cultural innovation, educational innovation is the fundamental driving force of cultural innovation. In this sense, any new forms of education must be accompanied by the generation of educational culture. In the cultural integration of education, cross-culture is irreplaceable in present teaching model.

\subsection{Promotion Of Interdisciplinary Education}

Now the cross-cultural art education and training systems are waiting for more breakthroughs and integrations. Combining the complexity of cultural flows and the diverse personal experiences of multiculturalism, it is necessary to establish a teaching method that combines multicultural and crossdisciplinary disciplines. In general, the groups with diverse cultural backgrounds can be divided by: the core are ethnic students, international students; follows by their own multicultural background teachers, they are in the context of a fixed art education to build a relatively perfect and stable Learn

Under a relatively static cultural context, a stable learning space was well established. In addition to the inherent knowledge system, a small number of "non-local" cultures are added as new elements. It is not only an opportunity for cultural integration for the carriers of diversified cultural palettes, but also a critical hold for the local cohorts to reconsider about their existing cultural paradigm. To accept or to reject, resulting in the generation of a more diversified set of attitudes toward the new sets of culture.

Orginating from the concept of STEM (Science, Technology, Engineering, Mathematics), STEAM education is now culminating the educational hierarchy in cultivating first-class talents of the 21st century. The concept of STEM encourages the development and improvement of science, technology, engineering and mathematics, and comprehensive capacities to enhance its global competitiveness. Joined by Arts in the new model of STEAM, the original model has now become even more comprehensive. It is one of the unquantifiable differences between human nature and machines that human's creativity, or art itself would usually come together with the spirit of trying out for the 
seemingly improbable. The infeasibility of arts embodies and expresses the unpredictable aspects of human thought going on in the brain. Early diversification within the cultural background brings forward the creation of a more complex framework. Through the integration of cross-domain creativity and multi-cultural references, a composite model can be achieved.

\section{Conclusion}

From the perspective of economics, the new economic growth theory introduces technological progress, human capital, and other factors into the concern of economic growth model, putting forward the assumptions of incremental income factor, comprehensively correcting and developing the neoclassical growth theory. It emphasizes that economic growth is the product of the internal forces of the economy, and focuses on the research of new problems such as technological progress, practical operation, knowledge accumulation, human capital and government expenditure. Quoting Douglas North's and James Buchanan's words, that the determinants of economic growth is institution and institutional innovation.

All in all, innovation for art education is a kind of education related to the content of "wisdom", performs in the "method" of create the ability of education. More and more people care about the cultivation of this ability, and one-way education is no longer able to meet today's global high-speed development of society. Through the complex multi-cultural background of the interaction, natural fermentation to cultivate the ability, are more suitable to today's social needs. Einstein has quoted a wit sentence to explain education: "Education is what remains after one has forgotten everything he learned in school." In other words, the details of knowledge can be recorded by books, the ability to learn knowledge and the ability to create knowledge, what have been forgotten is actually the essence of education.

\section{References}

[1]. Louis· Moure Danielle Lévy Images, words, and Characterization of cultural awareness

[2]. Samosud. Globalization and indigenization multicultural education: The empirical study of ethnic identity and national unity education, 2013 